\title{
Response of Triatoma infestans to pour-on cypermethrin applied to chickens under laboratory conditions
}

\author{
Ivana Amelotti ${ }^{+}$, Silvia S Catalá, David E Gorla \\ Centro Regional de Investigaciones Científicas y Transferencia Tecnológica de La Rioja (CRILAR), Entre Ríos y Mendoza s/n, 5301 \\ Anillaco, La Rioja, Argentina
}

This article reports the effects of a pour-on formulation of cypermethrin (6\% active ingredient) applied to chickens exposed to Triatoma infestans, the main vector of Chagas disease in rural houses of the Gran Chaco Region of South America. This study was designed as a completely random experiment with three experimental groups and five replicates. Third instar nymphs were fed on chickens treated with 0,1 and 2 cc of the formulation. Nymphs were allowed to feed on the chickens at different time intervals after the insecticide application. Third-instar nymphs fed on treated chickens showed a higher mortality, took less blood during feeding and had a lower moulting rate. The mortality rate was highest seven days after the insecticide solution application and blood intake was affected until 30 days after the application of the solution.

Key words: Triatoma infestans - vector control - Chagas disease - Gran Chaco - cypermethrin - pour-on formulation

The interruption of the vectorial transmission of Chagas disease in most of the Southern Cone countries of South America is a good example of a successful vector control programme at a sub-continental scale (Schofield et al. 2006). This is widely recognised and it is now clear that the last frontier for complete success is represented by the control of vector populations in rural houses in the Gran Chaco Region of Argentina, Bolivia and Paraguay. Besides economic and political circumstances that affected the vector control programmes in the area, the continued infestation of houses in the region is associated with the closeness of the dispersion centre of Triatoma infestans, which appears to be located in the intermediate Andean valleys of Bolivia and somewhere in the Chaco Region between Argentina and Bolivia (Schofield 1988, Panzera et al. 2004, Bargues et al. 2006, Catalá et al. 2007). This biogeographical feature is a likely cause of the resilience of the T. infestans populations in the area. Vector control programmes using the traditional pyrethroid spraying of intra and peridomestic structures of rural houses are not as successful as programmes outside the Chaco Region. Traditional spraying is highly effective inside domiciles, but it frequently leaves a number of residual peridomestic vector populations, as reported in the southern part of the Chaco Region by Porcasi et al. (2006, 2007). These residual populations eventually recolonise the domestic rooms and re-establish the domestic transmission cycle of Trypanosoma cruzi, as shown by Gurtler et al. (2007) in the central area of the Argentinean Chaco.

Financial support: CONICET and PICT 2006-878 (ANPCYT)

+Corresponding author: iamelotti@crilar-conicet.com.ar

I Amelotti, SS Catalá and DE Gorla are members of CONICET (Argentina). All authors contributed equally to this article.

Received 8 October 2008

Accepted 19 March 2009
A number of different approaches and techniques for controlling or eliminating peridomestic populations of T. infestans have been considered as alternatives to the traditional application of pyrethroid insecticides. Among other methods, habitat management (Gorla et al. 2005) and insecticide paints (Pinto Dias \& Jemmio 2008) are presently being studied. An early attempt, based on changing the structure of a goat corral, was carried out by Ronderos and Schnack (1987) after they recognised that this corral type was one of the main ecotopes contributing to the persistence of peridomestic T. infestans. Ronderos discontinued these studies; only recently have Gorla et al. (2005) begun using a similar approach to changing the corral structure to eliminate triatomine infestation and to increase the productivity of the goat hut as a way to increase acceptability and sustainability.

As an alternative to pyrethroid spraying, pour-on insecticide formulations have been widely used to control insects of medical and veterinary importance, such as Hematobia irritans (Guglielmone et al. 1999), tsetse flies (Glossina sp.) (Baylis \& Stevenson 1998, Rowlands et al. 2002), cattle ticks (Boophilus microplus) (Sosa 1985), malaria vectors (Anopheles sp.) (Hewitt \& Rowland 1999), lice (Pediculus sp.) (Levot 2000) and T. infestans (Gürtler et al. 2009).

Reithinger et al. $(2005,2006)$ reported that the use of rubber collars with $40 \mathrm{mg} / \mathrm{g}$ deltamethrin on dogs reduced the feeding success and the survival, fecundity and moulting rates of $T$. infestans, resulting in vector population extinction after 196 days.

Here we report the results of an experimental study that evaluates the blood intake, moulting and mortality rates of $T$. infestans fed on chickens that were treated with a pour-on formulation of cypermethrin.

\section{MATERIALS AND METHODS}

The study was carried out in the laboratory facilities of CRILAR (La Rioja, Argentina). The cypermethrin 
[R-S (cis-trans)-3-(2,2-dichlorovinyl) 2,2 dimethylcyclopropyl- (R-S) alphacyane-3- phenoxybenzyl carboxylate] was formulated as a pour-on solution with $6 \%$ active ingredient (a.i.) by Biogénesis S.A (Buenos Aires, Argentina) and commercialised as Aciendel ${ }^{\circledR}$.

Insects used in this study were third-instar nymphs of T. infestans provided by the breeding facility of the Coordinación Nacional de Control de Vectores in Punilla (Cordoba). The specimens were F1 offspring of $T$. infestans that were collected in the northern part of the San Luis province of Argentina, bred under controlled conditions and fed on chickens (Gallus sp.). The third-instar nymphs used in the experiments were 15 days post-moulting on average, unfed and kept under controlled temperature $\left(26-28^{\circ} \mathrm{C}\right)$ and humidity $(50-70 \% \mathrm{RH})$ in appropriately labelled plastic jars. The chickens used in this study weighed between 590 and 2,190 g and were fed with controlled quantities of a mix of natural grains (corn, sunflower and oat). The chickens were weighed every two weeks with an electric balance (accurate to $2 \mathrm{~g}$ ).

The experimental design included three groups $(2$ treated and 1 control) of five chickens each, randomly selected. Each chicken was identified and caged individually throughout the experiment. The insecticide was applied to the base of the neck with a needle-less syringe for chickens assigned to treated groups. One group of chickens was treated with $1 \mathrm{cc}(=0.06 \mathrm{~g}$ a.i. per chicken) of the pour-on formulation, and a second group was treated with $2 \mathrm{cc}(=0.12 \mathrm{~g}$ a.i. per chicken $)$ of the formulation. The control group was manipulated similarly but did not receive the insecticide. Each test of insecticide effectiveness was replicated using three jars with 10 third-instar nymphs each, fed over the individually identified chicken. A total of 150 third-instar nymphs (10 nymphs x 3 jars x 5 chickens) were used per experimental group on each feeding occasion.

We measured the effects of insecticide on blood intake, mortality and moulting rates of the third-instar nymphs. The residual effect of the insecticide was measured using five independent groups of nymphs fed one, seven, 20, 30 and 45 days after the pour-on application. Nymphs of each independent group were fed three times at days zero, 17 and 34 of the specified date of the pour-on application on the same chicken (i.e. 1st group with 1st contact at day 1 after the pour-on application was fed at days 1, 17 and 34; 2 nd group, 1st contact at day 7 after the pour-on application was fed at days 7, 21 and 41 etc.).

T. infestans nymphs were allowed to feed for $15 \mathrm{~min}$ using a device that immobilised the chicken and allowed the insects to insert their mouthparts into the ventral part of the animal through a nylon mesh. Blood intake was calculated as the difference between the weights of the plastic jars before and after each feeding, divided by the number of living nymphs in each jar. The nymphs were weighed as a group and not individually to avoid excessive manipulation that could artificially increase the mortality rate.

Mortality and moults were recorded weekly and evaluated 14 days after contact with a treated chicken to allow for the eventual recovery of knocked-down in- dividuals that received sub-lethal pyrethroid doses (Alzogaray \& Zerba 1997).

Data were analysed with parametric ANOVA, where variance heterogeneity was rejected (Levene test). Cases with heterogeneous variances were analysed with the Kruskal-Wallis test. All statistical calculations were carried out with Infostat 2004.

\section{RESULTS}

The insecticide produced differential mortality rates in the nymphs during the first week after the pour-on application, but not afterwards (Fig. 1). Nymphs fed with treated chickens seven days after the insecticide application showed a higher mortality rate than the nymphs in the control group $(\mathrm{p}<0.01)$. Nymphs fed on chickens treated with $2 \mathrm{cc}$ of the pour-on solution showed a higher mortality rate than nymphs of the $1 \mathrm{cc}$ group $(53.4 \pm 17.6 \%$ and $29 \pm 3 \%$, respectively, $\mathrm{p}<0.01$ ). Nymphs fed 20,30 and 45 days after the pour-on application did not show differences in mortality between treated and control groups. The mortality rate of the nymphs in the control replicates averaged $4.96 \pm 5.68 \%$. These values are within the expected mortality of laboratory-reared individuals.

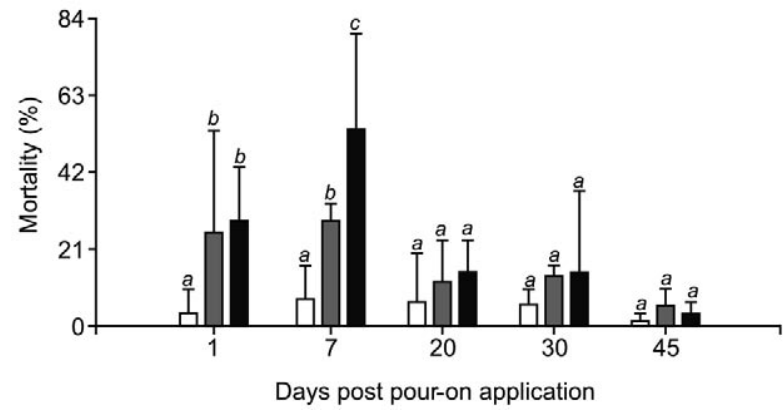

Fig.1: mortality (\%) of independent groups of 30 third instar Triatoma infestans nymphs fed at different intervals after the pour-on application. White bars: control group; grey bars: 1 cc group; black bars: 2 cc group. Different letters indicate groups differing significantly at $\mathrm{p}>$ 0.05 . Lines over the bars are standard deviations.

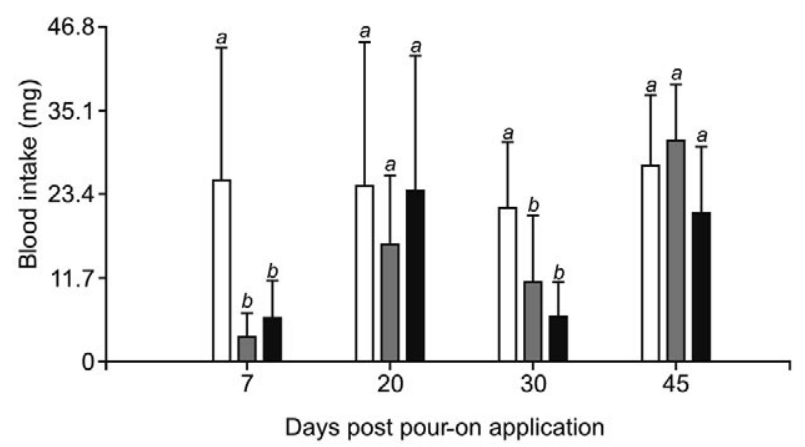

Fig.2: blood intake of third instars Triatoma infestans nymphs fed at different moments after the pour-on application. White bars: control group; grey bars: $1 \mathrm{cc}$ group; black bars: $2 \mathrm{cc}$ group. Different letters indicate groups differing significantly at $p>0.05$. Lines over the bars are standard deviations. 


\section{TABLE I}

Blood intake (mg) by third instar nymphs of Triatoma infestans in the second and third feeding occasions over control and treated chicken $(2 \mathrm{cc}$ and $1 \mathrm{cc})$ at different intervals after the pour-on application

\begin{tabular}{|c|c|c|c|c|}
\hline \multirow[b]{2}{*}{ Feeding occasion $^{a}$} & \multirow[b]{2}{*}{$\begin{array}{l}\text { Days post pour-on } \\
\text { application }\end{array}$} & \multicolumn{3}{|c|}{$\begin{array}{l}\text { Blood intake in each experimental group } \\
\text { average (standard deviation) }\end{array}$} \\
\hline & & $\begin{array}{c}2 \mathrm{cc} \\
(0.12 \mathrm{~g} \mathrm{a} . \mathrm{i})\end{array}$ & $\begin{array}{c}1 \mathrm{cc} \\
(0.06 \mathrm{~g} \mathrm{a} \text { a.i) }\end{array}$ & Control \\
\hline \multirow[t]{5}{*}{ Second } & 18 & $4.73(3.4)^{b}$ & $6.96(8.4)^{b}$ & $29.32(18.7)^{a}$ \\
\hline & 24 & $8.38(6.6)^{b}$ & $16.36(10.2)^{a}$ & $18.74(13.6)^{a}$ \\
\hline & 37 & $16.12(10.4)^{b}$ & $37.7(23.4)^{a}$ & $31.86(14.0)^{a}$ \\
\hline & 47 & $19.74(7.2)^{a}$ & $16.7(9.7)^{a}$ & $18.08(14.9)^{a}$ \\
\hline & 62 & $39.8(10.6)^{a}$ & $38.9(5.3)^{a}$ & $29.4(11.8)^{a}$ \\
\hline \multirow[t]{4}{*}{ Third } & 35 & $4.85(5.2)^{b}$ & $6.78(10.1)^{b}$ & $21.56(16.24)^{a}$ \\
\hline & 41 & $5.25(7.5)^{b}$ & $25.18(18.7)^{a}$ & $28.9(19.1)^{a}$ \\
\hline & 54 & $15.8(13.4)^{b}$ & $10.6(8.9)^{b}$ & $31.1(19.6)^{a}$ \\
\hline & 64 & $25.37(12.3)^{b}$ & $23.4(10.8)^{b}$ & $63.36(18.9)^{a}$ \\
\hline
\end{tabular}

$a$ : first feeding was offered one, seven, 20,30 and 45 days after the pour-on application to independent nymph groups. Each group received a second and third blood offer 17 and 34 days after the first blood offer, respectively. Same letters denote homogeneous groups within the same date, $\mathrm{p}>0.05$, Kruskal Wallis.

Blood intake in the first feeding seven days after the pour-on application was significantly higher in the control group than in both treated groups (Fig. 2). Blood intake by nymphs of the two treated groups was similar $(p>0.05)$. No difference in blood intake was found between control and treated groups fed 20 and 45 days after the pour-on application. On average, each nymph of the control group that was fed 7-45 days after the pouron application consumed $24.7 \pm 15 \mathrm{mg}$ of blood (Fig. 2). Nymphs of the control group consumed more blood than nymphs of the treated groups for up to 64 days after the pour-on application (Table I).

The moulting rate was significantly higher in the nymphs of the control group than in the nymphs fed on treated chickens during the first seven days after the pouron application. No differences were found between treated and control nymphs after the seventh day (Table II).

\section{DISCUSSION}

The active ingredient of pour-on formulations is sequestered by the sebaceous glands of the animal's skin and then gradually released from these reservoirs over a two-month period in concentrations high enough to kill resident parasites on the skin (Brayden 2003). However, the precise mechanism is probably a mixture of the effects produced by the active ingredient diffusing through and mechanically spreading over the surface of the animal's skin. This study showed that a pour-on formulation of $6 \%$ cypermethrin applied to chickens produces a high mortality rate and decreases blood intake and moulting rates for T. infestans nymphs under laboratory conditions during the first seven days after the pour-on application.

Third instar nymphs fed on chickens treated with 1 or $2 \mathrm{cc}$ of cypermethrin solution showed a maximum mortality rate of $53.4 \%$ after three meals on the same chicken. This observed mortality rate is high, considering that the nymphs contacted the chicken only with the
TABLE II

Moulting rate (\%) in independent groups of third instar nymphs of Triatoma infestans fed over control and treated groups $(2 \mathrm{cc}$ and $1 \mathrm{cc}) 34$ days after the first meal

Moulting rate in each experimental group average (standard deviation)

\begin{tabular}{|c|c|c|c|}
\hline $\begin{array}{l}\text { Days post pour-on } \\
\text { application }\end{array}$ & $\begin{array}{c}2 \mathrm{cc} \\
(0.12 \mathrm{~g} \text { a.i })\end{array}$ & $\begin{array}{c}1 \mathrm{cc} \\
(0.06 \mathrm{~g} \mathrm{a.i})\end{array}$ & Control \\
\hline 1 & $3(4)^{b}$ & $4.7(5)^{b}$ & $32(25)^{a}$ \\
\hline 7 & $5(1)^{b}$ & $23(2)^{a}$ & $20(15)^{a}$ \\
\hline 20 & $9(16)^{a}$ & $18(20)^{a}$ & $43(27)^{a}$ \\
\hline 35 & $2(2)^{a}$ & $2(4)^{a}$ & $5(6)^{a}$ \\
\hline 45 & $15(1)^{a}$ & $37(1)^{a}$ & $31(15)^{a}$ \\
\hline
\end{tabular}

same letters denote homogeneous groups within the same date, $\mathrm{p}>0.05$, Kruskal Wallis.

rostrum, through the nylon mesh jar cover and on a region of the chicken's body relatively far away from the point where the pour-on solution was applied. (Nymphs were fed on the chicken's abdomen, while the pour-on was applied to the base of the chicken's neck.) It was expected that the active ingredient would diffuse throughout the chicken's body and would reach the ventral region where the nymphs were allowed to feed. Preliminary experiments done by our group (data not shown) suggest that diffusion of the active ingredient may not be sufficient to produce the concentration needed to kill triatomines. If this is confirmed, the insecticide application location and/or dose/response studies should be reconsidered.

The blood intake by treated nymphs was lower than the blood intake of control nymphs by a factor of 2 . Nymphs fed on treated chickens took $15.1 \pm 14.4 \mathrm{mg}$ of blood on each occasion, whereas nymphs fed on control 
chickens took $36.2 \pm 24.2 \mathrm{mg}$. This effect might be due to a repellence response, as seen in Triatoma sordida up to 120 days after the application of $2.5 \mathrm{mg} / \mathrm{m}^{2}$ of deltamethrin (Diotaiuti et al. 2000). Similarly, Alzogaray et al. (2000) showed that a repellent component inhibits the feeding of $T$. infestans third-instar nymphs.

Degradation of cypermethrin begins immediately after its application and its abiotic degradation time is about four weeks (WHO 1989). The residual activity of the cypermethrin pour-on may vary, as Heath et al. (1992) reported an insecticide effect on Bovicola ovis until 16 weeks post-treatment in sheep (Ovis aries). In this study, the highest mortality was observed between seven-15 days after the pour-on solution application. The absence of higher mortality before day 7 might be attributed to insecticide repellence. Apparently, the repellence dies off more quickly than the residual activity, causing mortality in the nymphs. The repellence decreased but did not disappear, as shown by the low values of the blood intake for control and treated groups over most of the 45 days studied in the experiments. It is well known that blood intake is one of the key factors regulating the density of natural populations of $T$. infestans (Schofield 1982, 1985, Gorla \& Schofield 1989) and that the amount of blood taken by the individuals of a natural population is strongly affected by intraspecific competition, which is mediated by host irritability. The amount of ingested blood affects the development rate of nymphal stages, female fecundity, mortality and dispersal rates in T. infestans (Lehane et al. 1992, Schofield et al. 1992, Vazquez Prokopec et al. 2004), consequently affecting the population growth rate. Results of this study showed that treated third-instar nymphs had a lower moulting rate than controls. One undesirable effect of this type of potential tool for triatomine control is its eventual effect on adult dispersal due to of the low nutritional status that it might promote. This should be considered in future studies.

This study shows that the pour-on formulation of cypermethrin decreases rates of nymph survival, development and blood ingestion, although the formulation did not totally eliminate a population under the experimental conditions used in this study. Future studies are needed to evaluate the effects of pour-on formulations in field conditions, where the insects would be in closer contact to the chickens. The pour-on formulation is an approach that may complement traditional pyrethroid spraying which showed low efficacy in the elimination of $T$. infestans populations occupying peridomestic structures of rural houses of the Gran Chaco Region of Argentina.

\section{ACKNOWLEDGEMENTS}

To Raúl Stariolo (Centro de Referencia de Vectores, Coordinación Nacional de Control de Vectores), for the provision of the insects, to Rodrigo Gonzalez Llanos (Chemotecnica), for the provision of the insecticide, to Luciana Abrahan, Laura Hernandez and Natalia Folguera, for the support during laboratory work, to Claudia Vassena, for her helpful comments.

\section{REFERENCES}

Alzogaray RA, Fontan A, Zerba, EN 2000. Repellency of deet to nymphs of Triatoma infestans. Med Vet Entomol 14: 6-10.
Alzogaray RA, Zerba EN 1997. Incoordination, paralysis and recovery after pyrethroid treatment on nymphs III of Triatoma infestans (Hemiptera: Reduviidae). Mem Inst Oswaldo Cruz 92: 431-435.

Bargues MD, Klisiowicz DR, Panzera F, Noireau F, Marcilla A, Pérez R, Rojas MG, O’Connor JE, Gonzalez-Candelas F, Galvao C, Jurberg J, Carcavallo RU, Dujardin JP, Mas-Coma S 2006. Origin and phylogeography of the Chagas disease main vector Triatoma infestans based on nuclear rDNA sequences and genome size. Infect Genet Evol 6: 46-62.

Baylis M, Stevenson P 1998. Trypanosomiasis and tsetse control with insecticidal pour-ons - fact and fiction? Parasitol Today 14: 77-82.

Brayden DJ 2003. Novel drug delivery strategies in veterinary medicine - Review. Ir Vet J 56: 310-316.

Catalá S, Gorla DE, Juarez P, Picollo MI, Panzera F, Noireau F, Rojas Cortes M, Dujardin JP, Zerba E, Vassena C, Perez R, Calderón L, Abrahan L, Hernández ML, Cardozo R, Lopez E, Porcasi X, Moreno M, Schachter Broide J, Gürtler R, Lucero C, Ferrandis I, Calleros L, Ferreiro MJ, Cardozo L, Girotti J, Mijailovski S, Richer W, Kengne P, Perrineau MM, Cahuet A, Fontenille D, Herrera B, Gentile A, Gemio A, Alderete P, Diosque P, Acosta N, Alcaraz P, Llanos A, Uncos A 2007. Analytical appraisal, Southern Cone - biological and environmental causes of the spatial structuration in Triatoma infestans and the implications for vector control programmes. In: Proceedings SSA/EC American Trypanosomiasis Update Workshop, Asunción, Paraguay, p. 13-18.

Diotaiuti L, Marques Penido C, Saravia de Araujo H, Schofield C, Texeira Pinto C 2000. Excito-repellency effect of deltamethrin on triatomines under laboratory conditions. Rev Soc Bras Med Trop 33: 247-252.

Gorla DE, Catalá SS, Porcasi X, Moreno M, Abrahan L, Carrizo H 2005. Manejo ambiental de estructuras peridomésticas para eliminar la infestación por Triatoma infestans en Los Llanos de La Rioja,Technical Report to Programa Vigia, Ministerio Salud Argentina, 7 pp.

Gorla DE, Schofield CJ 1989. Population dynamics of Triatoma infestans under natural climatic conditions in the Argentine Chaco. Med Vet Entomol 3: 179-194.

Guglielmone AA, Castelli ME, Volpogni MM, Anziani OS, Flores SG 1999. Cypermethrin pour-on synergized with piperonyl butoxide: effects on Haematobia irritans (Diptera: Muscidae) natural populations resistant to cypermethrin. Vet Parasitol 83: 65-72.

Gürtler RE, Ceballos LA, Stariolo R, Kitron U, Reithinger R 2009. Effects of topical application of fipronil spot-on on dogs against the Chagas disease vector Triatoma infestans. Trans $R$ Soc Trop Med Hyg 103: 298-304.

Gürtler RE, Kitron U, Cecere MC, Segura EL, Cohen JE 2007. Sustainable vector control and management of Chagas disease in the Gran Chaco, Argentina. Proc Natl Acad Sci USA 104: 16194-16199.

Heath AC, Nottingham RM, Bishop DM, Cole DJ 1992. An evaluation of two cypermethrin-based pour-on formulations on sheep infected with the biting louse, Bovicola ovis. NZ Vet J 40: 104-106.

Hewitt S, Rowland M 1999. Control of zoophilic malaria vectors by applying pyrethroid insecticides to cattle. Trop Med Int Health 7: 481-486.

InfoStat 2004. InfoStat version 2004. Grupo InfoStat, FCA, Universidad Nacional de Córdoba, Argentina.

Lehane MJ, McEwen PK, Whitaker CJ, Schofield CJ 1992. The role of temperature and nutritional status in flight initiation by Triatoma infestans. Acta Trop 52: 27-38.

Levot G 2000. Resistance and the control of lice on humans and production animals. Int J Parasitol 30: 291-297. 
Panzera F, Dujardin JP, Nicolini P, Caraccio MN, Rose V, Tellez T, Bermudez H, Bargues MD, Mas-Coma S, O'Connor JE, Pérez R 2004. Genomic changes of Chagas disease vector, South America. Emerg Infect Dis 10: 439-446.

Pinto Dias JC, Jemmio A 2008. Sobre uma pintura inseticida para o controle de Triatoma infestans na Bolívia. Rev Soc Bras Med Trop 41: 79-81.

Porcasi X, Catalá SS, Hrellac H, Scavuzzo MC, Gorla DE 2006. Infestation of rural houses by Triatoma infestans (Hemipera: Reduviidae) in the southern area of the Gran Chaco in Argentina. $J$ Med Entomol 43: 1060-1067.

Porcasi X, Hrellac H, Catalá S, Moreno M, Abrahan L, Hernandez L, Gorla DE 2007. Infestation of rural houses by Triatoma infestans in the region of Los Llanos (La Rioja, Argentina). Mem Inst Oswaldo Cruz 102: 63-68.

Reithinger R, Ceballos L, Stariolo R, Davies CR, Gürtler RE 2005. Chagas disease control: deltamethrin-treated collars reduce Triatoma infestans feeding success on dogs. Trans R Soc Trop Med Hyg 99: 502-508.

Reithinger R, Ceballos L, Stariolo R, Davies CR, Gürtler RE 2006. Extinction of experimental Triatoma infestans populations following continuous exposure to dogs wearing deltamethrin-treated collars. Am J Trop Med Hyg 74: 766-771.

Ronderos RA, Schnack JA 1987. Ecological aspects of Triatominae in Argentina. In RR Brenner, A Stoka (eds.), Chagas' Disease Vectors, CRC Press Inc, USA, p. 85-97.
Rowlands GJ, Leak SGA, Mulatu W, Nagda SM, Wilson A, d'Ieteren GDM 2002. Use of deltamethrin 'pour-on' insecticide for the control of cattle trypanosomosis in the presence of high tsetse invasion. Med Vet Entomol 15: 87-96.

Schofield CJ 1982. The role of blood intake in density regulation of populations of Triatoma infestans (Klug) (Hemiptera: Reduviidae). Bull Entomol Res 72: 617-629.

Schofield CJ 1985. Population dynamics and control of Triatoma infestans. Ann Soc Belg Med Trop 65: 149-164.

Schofield CJ 1988. The biosystematics of Triatominae. In MW Service (eds.), Biosystematics of haematophagous insects, Systematics Association/Clarendon Press, Oxford, p. 284-312.

Schofield CJ, Jannin J, Salvatella R 2006. The future of Chagas disease control. Trends Parasitol 22: 583-588.

Schofield CF, Lehane MJ, McEwen P, Catalá SS, Gorla DE 1992. Dispersive flight by Triatoma infestans under natural climatic conditions in Argentina. Med Vet Entomol 6: 51-56.

Sosa E 1985. Evaluating the efficacy and residual effect of flumethrine pour-on against Boophilus microplus in cattle in Uruguay. Vet Med Nachr 2: 126-131.

Vazquez-Prokopec GM, Ceballos LA, Kitron U, Gürtler RE 2004. Active dispersal of natural populations of Triatoma infestans (Hemiptera: Reduviidae) in rural Northwestern Argentina. J Med Entomol 41: 614-621.

WHO - World Health Organization 1989. Cypermethrin. Avaible from: http://www.inchem.org/documents/hsg/hsg/hsg022.htm. 